\title{
The Climate Crisis and the Exam Room
}

\author{
Katherine C. Brooks, MD (1) \\ Zuckerberg San Francisco General Hospital, University of California San Francisco, San Francisco, CA, USA.
}

J Gen Intern Med 35(10):3069-70

DOI: $10.1007 / \mathrm{s} 11606-020-06050-3$

(c) Society of General Internal Medicine 2020

$\mathrm{T}$ he summer after our daughter was born, my family traveled to my husband's home of Puerto Rico. It was nearly two years after Hurricane Maria had devastated the island with unprecedented force and the impact was still visible throughout the island. One hot humid night in San Juan, we sat in my sister-in-law's un-air-conditioned kitchen, monitoring a circling tropical storm and hoping we would make it back to the continental US before it struck land.

All of a sudden, it struck me. The echoes of Hurricane Maria, the hotter than usual summer temperatures, and the early tropical storm all reminded me of one thing: our changing climate. My daughter would turn 31 in 2050, when recent data predicts that a quarter of the world's cities will experience climate conditions not present anywhere on earth today. ${ }^{1}$

The questions started flying. Would my daughter feel safe on this planet? Would she be able to explore the world like I had? Had my husband and I been selfish in creating this small beautiful being?

I admit I had taken a rather cavalier approach to the climate crisis throughout much of my life. I had spent 10 years of my youth becoming a doctor and I had somehow managed to frame climate change as a threat to the polar bears and the ice caps, but not to my patients or my family. Throughout my medical training, no one had had forced me to see the profound connection between a changing climate and my new profession.

As helplessness set in, my motherly instincts began to shift from how to protect my daughter against sunburns and viruses, to how to protect a healthy future for her on this planet. At home, healthy choices took on new meaning - compost over trash, electric vehicles over student loans, chicken over beef.

When my maternity leave ended, I started my first attending position at a county hospital. While I had once used my profession as an excuse for inaction, I started to wonder what the role of a doctor should be in addressing this crisis, and why

Received February 5, 2020

Accepted July 10, 2020

Published online July 27, 2020 we aren't talking about it more- - both amongst ourselves and with our patients.

WHO estimates that between the years 2030 and 2050, 250,000 annual deaths will be attributed to climate change. ${ }^{2}$ Rising temperatures will cause heat-related illness and death and lead to disruptions in food supply causing malnutrition. Air pollution will influence the incidence and severity of diseases like asthma, COPD, heart disease, and cancer. And survivors of natural disasters will experience sometimes ongoing and recurrent trauma. ${ }^{3}$

Doctors are increasingly concerned about climate change and have proposed important roles in disease surveillance, policy advocacy, and healthcare reform. Yet, physicians' voices are powerful not only in op-eds, research, and advocacy, but in the quiet trusted spaces of our exam rooms. What if we started to talk about climate change in our daily visits with patients?

What kind of a vehicle do you drive? How do you heat your home? How many times a year do you fly on a plane? How much of your diet comes from animals?

How do you see your health being impacted by worsening pollution?

Do you worry about the future of the planet, and are these worries impacting your mental health?

How can I help you prepare to protect your family during the next natural disaster?

There are many reasons to ask these questions. Studies have found that reframing the climate crisis as a public health threat, and presenting tangible threats such as illness, may increase buy-in from the millions of Americans who are skeptical. ${ }^{4}$ Patients may be wondering what they can do to counter threats to their environment and appreciate the data-driven opinion of their physician. Others may be anxious and need support. Conveniently, any advice I give to follow a sustainable plant-based diet or choose carbon-free transportation can only positively impact my patient's individual health as well.

These questions may be best posed in routine primary care visits - as a part of our social history and preventative screening tools. They could be discussed by specialists in relationship to chronic conditions that may be worsened by the changing climate. In the hospital, an exacerbation of asthma or heart failure may be a good moment to take a step back and evaluate the influences of the environment and what the patient can do to address them. 
These conversations will be difficult at first. They may feel awkward or strained. They may feel burdensome to providers already tasked with competing priorities in too little time. To some patients focused on today's survival, these questions may seem irrelevant.

But despite these challenges, even a brief mention of the climate in a medical visit may have a profound impact. Since 1964, when the surgeon general formally proclaimed the health risks of smoking, an estimated 8 million cigaretteassociated deaths have been prevented, much of it through patient education. ${ }^{5}$ While it may once have seemed intrusive to ask about cigarette smoking, it is now entirely routine and integrated in some way into almost every clinical visit and hospitalization. By making questions around climate change routine and universal, patients will begin to associate that what is healthy for the planet is healthy for them as well. ${ }^{3}$

As with all counseling and patient education, we must pick our moments. We must be sensitive to national variability in access to clean energy as well as the economic privilege needed to afford the most advanced green technology. We must recognize that low-income people of color are always the first to be affected by natural disasters, pollution, and the effects of extreme heat, yet often have few resources to prevent and prepare. We must also realize that individual action will not solve this crisis, but that widespread grassroots advocacy is needed before meaningful corporate and political action will take place.

At a time where politics complicates reality, these conversations make it clear to our patients we speak of indisputable science, not personal opinion. The most recent report from the Intergovernmental Panel on Climate Change found that we have only 10 years left to prevent catastrophic and irreversible damage. ${ }^{6}$ Political and corporate change of large enough scale will not occur without enormous grassroots pressure from all professions and industries. The CDC estimates that $84 \%$ of Americans see a physician every year. ${ }^{7}$ That means we reach
275 million people annually. Thus, of all professionals, doctors may actually be the most uniquely positioned to change enough minds in time.

So regardless of our politics, where we trained or where we practice, doctors share roots in science and service. The planet is warming and our patients are getting sicker. We must convince our patients that their life and the planet's life are quickly becoming indistinguishable.

Corresponding Author: Katherine C. Brooks, MD; Zuckerberg San Francisco General Hospital, University of California San Francisco, San Francisco, CA, USA (e-mail: katherine.brooks@ucsf.edu).

Compliance with Ethical Standards:

Conflict of Interest: The author declares that she does not have a conflict of interest.

\section{REFERENCES}

1. Bastin JF, Clark E, Elliott T, et al. Understanding climate change from a global analysis of city analogues. PLoS One. 2019;14(7):e0217592.

2. Organization WH. WHO Health and Climate Change Survey ReportTracking Global Progress. 2019.

3. Haines A, Ebi $\mathbf{K}$. The Imperative for Climate Action to Protect Health. $N$ Engl J Med. 2019;380(3):263-273.

4. Kotcher J, Maibach E, Montoro M, Hassol SJ. How Americans Respond to Information About Global Warming’s Health Impacts: Evidence From a National Survey Experiment. Geohealth. 2018;2(9):262-275.

5. Holford TR, Meza R, Warner KE, et al. Tobacco control and the reduction in smoking-related premature deaths in the United States, 1964-2012. JAMA. 2014;311(2): 164-171.

6. Change IPoC. Summary for Policymakers of IPCC Special Report on Global Warming of $1.5^{\circ} \mathrm{C}$ approved by governments. 2018 .

7. Control CfD. Summary Health Statistics Tables for U.S. Adults: National Health Interview Survey. 2018.

Publisher's Note: Springer Nature remains neutral with regard to jurisdictional claims in published maps and institutional affiliations. 